\title{
A Simple Automated Method for the Determination of Nitrate and Nitrite in Infant Formula and Milk Powder Using Sequential Injection Analysis
}

\author{
Mariela Pistón, Alicia Mollo, and Moisés Knochen \\ Analytical Chemistry, DEC, School of Chemistry, University of the Republic (UdelaR), Avenida Flores 2124, \\ 11800 Montevideo, Uruguay \\ Correspondence should be addressed to Mariela Pistón, mpiston@fq.edu.uy
}

Received 30 March 2011; Revised 15 June 2011; Accepted 16 June 2011

Academic Editor: Jaroon Jakmunee

Copyright () 2011 Mariela Pistón et al. This is an open access article distributed under the Creative Commons Attribution License, which permits unrestricted use, distribution, and reproduction in any medium, provided the original work is properly cited.

A fast and efficient automated method using a sequential injection analysis (SIA) system, based on the Griess, reaction was developed for the determination of nitrate and nitrite in infant formulas and milk powder. The system enables to mix a measured amount of sample (previously constituted in the liquid form and deproteinized) with the chromogenic reagent to produce a colored substance whose absorbance was recorded. For nitrate determination, an on-line prereduction step was added by passing the sample through a Cd minicolumn. The system was controlled from a PC by means of a user-friendly program. Figures of merit include linearity $\left(r^{2}>0.999\right.$ for both analytes), limits of detection $\left(0.32 \mathrm{mg} \mathrm{kg}^{-1} \mathrm{NO}_{3}-\mathrm{N}\right.$, and $\left.0.05 \mathrm{mg} \mathrm{kg}^{-1} \mathrm{NO}_{2}-\mathrm{N}\right)$, and precision $\left(s_{r} \%\right)$ 0.8-3.0. Results were statistically in good agreement with those obtained with the reference ISO-IDF method. The sampling frequency was 30 hour $^{-1}$ (nitrate) and 80 hour $^{-1}$ (nitrite) when performed separately.

\section{Introduction}

Nitrate and nitrite when ingested by human beings may have a negative impact on health. Nitrate is transformed to nitrite by the action of certain microorganisms present in the intestine. Then it may transform hemoglobin to methemoglobin by oxidizing $\mathrm{Fe}$ (II) present in the former substance to $\mathrm{Fe}$ (III). Methemoglobin is unable to carry oxygen thus originating a condition called methemoglobinemia, characterized by hypoxia.

Young children are more prone to this condition, thus it is important to control the levels of nitrate and nitrite in milk and infant formulas consumed by the children and infants during lactation period, especially those without breastfeeding.

Nitrate may appear in dried milk and infant formulas as a consequence of the industrial process, as a contaminant of the salts added in the manufacture of fortified milks and infant formulas.

Nitrite, on the other hand, is a consequence of microbial contamination or may be added during the manufacturing process. Powdered infant formulas are not commercially sterile products, they are heat treated during processing, but unlike liquid products, they are not exposed to high temperatures for sufficient time to make the final packaged product commercially sterile.

A search in the scientific literature has shown few papers dealing with methods for the determination of nitrate and nitrite in infant formula or milk powder samples. Gas chromatography [1] and spectrophotometry [2] have been proposed for this purpose in papers published long time ago.

On the other hand, the ISO-IDF standard method [3] consists of a colorimetric determination for nitrite, based on the classical reaction with $\mathrm{N}$-(1-Naphthyl)ethylenediamine and sulfanilamide. Nitrate in turn is reduced to nitrite by means of a cadmium column. Nitrite is then determined colorimetrically as explained before. Previous sample preparation consists of a precipitation step where fat and proteins are separated.

Currently, analytical laboratories experience an increasing demand for a large number of analytical determinations which are expected to be carried out in a fast and accurate 
way. Procedures such as those mentioned before rely heavily on the use of hand labor and are inherently slow and thus may hinder the required laboratory productivity.

On the other hand, the demand for high productivity can be satisfied by resorting to laboratory automation [4], which can be implemented in an easy and inexpensive way by means of flow-based techniques such as flow injection analysis (FIA) [5] or sequential injection analysis (SIA) [6]. The current ISO-IDF standard method is primarily carried out as a conventional manual procedure [7], but the standard allows for the possibility of automation by segmented flow analysis (SFA) [8], or flow injection analysis (FIA) [9]. Despite being very useful automation tools and presenting lower reagent consumption when compared to traditional batch methods, both SFA and FIA still resort to the use of a continuous flow of reagent, this being wasted in the periods between sample injections. Also, the use of peristaltic pumps requires preventive maintenance with frequent replacement of the pump tubing in order to avoid degradation in the quality of the results.

Despite having been developed primarily as a tool for process control, SIA also has found a place in the analytical laboratory, because of its inherent advantages such as robustness, reliability, and low consumption of sample and reagents. It is also based on the use of a syringe pump, which is highly dependable, requiring less maintenance than peristaltic pumps and having excellent repeatability when used to measure small volumes. It has been used successfully in the determination of nitrate and nitrite in matrixes such as water samples [10-12].

It has also been proposed for the analysis of different kinds of food samples [13]. Reis Lima et al. developed an SIA system for determining nitrate and nitrite in dairy products; however, the system uses two peristaltic pumps which results in a complicated system and has the disadvantages of using this type of pumps [14].

In this work, a simple SIA system that uses only one syringe pump was developed for the determination of nitrate and nitrite in infant formula and milk powder for quality control purposes. This automated system was more precise and faster than the antecedent mentioned with less effluent generation for these kinds of determinations. Total control from a PC was achieved using modern programming languages and with user-friendly graphical interfaces.

\section{Experimental}

The following reagents used were of analytical-reagent grade: potassium hexacyanoferrate (II) trihydrate, zinc sulfate heptahydrate, N-(1-Naphtyl)ethylenediamine dihydrochloride (NED), sulfanilamide, phosphoric acid 85\%, ammonium chloride, ammonium hydroxide, disodium ethylenediamine tetraacetate (EDTA), potassium nitrate, and potassium nitrite. Glass-distilled water, further purified in a Millipore (São Paulo, Brazil) Simplicity 185 water purifier, was used throughout.

Standard nitrate and nitrite solutions were prepared daily by dilution of stock solutions of nitrate and nitrite (100 $\mathrm{mg} \mathrm{L}^{-1} \mathrm{NO}_{3}-\mathrm{N}$ and $\mathrm{NO}_{2}-\mathrm{N}$, resp.) prepared from the respective sodium salts. Nitrite content of the stock solution was determined volumetrically.

A buffer solution was prepared by dissolving in distilled water $13 \mathrm{~g}$ of $\mathrm{NH}_{4} \mathrm{Cl}, 1.7 \mathrm{~g}$ of EDTA per liter. The $\mathrm{pH}$ was adjusted to 8.5 with $\mathrm{NH}_{4} \mathrm{OH}$.

As it is described in ISO Standard 14673-1:2004/IDF Standard 189-1:2004, sample preparation consists of a precipitation step where fat and proteins are separated from the bulk solution. For that purpose, an exact amount of approximately $10 \mathrm{~g}$ of homogenized sample (dried milk or infant formula) was prepared as described in the official ISO-IDF procedure [7]. This test sample was transferred quantitatively to a $500 \mathrm{~mL}$ conical flask. Progressively $164 \mathrm{~mL}$ of purified water at $50-55^{\circ} \mathrm{C}$ was added with continuous stirring; then $6 \mathrm{~mL}$ of a solution of zinc sulfate heptahydrate $53.5 \%(\mathrm{w} / \mathrm{v}), 6 \mathrm{~mL}$ of a solution of potassium hexacyanoferrate (II) trihydrate $17.2 \%$ (w/v), and $20 \mathrm{~mL}$ of an ammoniacal buffer solution ( $\mathrm{pH}$ 9.69.7) were added. After stirring for three minutes, the protein and fat precipitate was filtered by means of nitrate-free filter paper. The procedure for preparation of the samples was basically the same described in ISO-IDF method. The filtrate was divided into two parts, one for determining nitrate and nitrite by the reference method [7] and the other for determination by the proposed SIA method.

The SIA system (Figure 1) consisted of a microprocessorcontrolled syringe pump (Cavro, Sunnyvale, Calif, USA, model XP-3000) featuring a two-position valve, and a $2.5 \mathrm{~mL}$ barrel, a Valco (Houston, Tex, USA) Cheminert 10-port selector valve with microelectric actuator, and a spectrophotometer fitted with a $200 \mu \mathrm{L}$ (internal volume) flow cell as detector. PFA tubing ( $0.8 \mathrm{~mm}$ ID) was used for connections, coiled mixing reactors, and holding coil. A minicolumn made of glass tubing (length $50 \mathrm{~mm}$, internal diameter $2.1 \mathrm{~mm}$ ) packed with cadmium granules; particle size $0.3-$ $1.6 \mathrm{~mm}$ (Fluka, Buchs, Switzerland) was used as reducing agent for nitrate determinations.

Control of the system and data acquisition were carried out by means of an IBM-compatible PC (Pentium III$600 \mathrm{MHz}$ ) with 2 serial ports, fitted with a 12-bit analog-todigital (A/D) interface card (Measurement Computing CIODAS08Jr) and a program compiled in Visual Basic 6.0. The program allowed control of the syringe pump and selector valve via the RS-232 serial ports and capture of analog data from the spectrophotometer which were scaled, transformed into absorbance, displayed on screen in real time, and saved to file on hard disk for later processing. Since the spectrophotometer used only provides an analog signal proportional to light intensity, it is necessary to carry out the definition of the photometric scale before beginning operation. For this purpose, the "dark signal" $\left(S_{d}\right)$ is measured and memorized with the shutter closed, then the " $100 \%$ T" or reference signal $\left(S_{\text {Ref }}\right)$ is measured and memorized with the shutter open and the flow cell filled with water. Afterwards, each time the A/D interface is triggered and the signal $\left(S_{x}\right)$ measured, absorbance is calculated by the software using the equation $A=\left(S_{x}-S_{d}\right) /\left(S_{\mathrm{Ref}}-S_{d}\right)$ and used for all operations. The setup screen provides for these routines.

Nitrite was determined by reaction with N-(1-Naphthyl) ethylenediamine and sulfanilamide and measurement of 


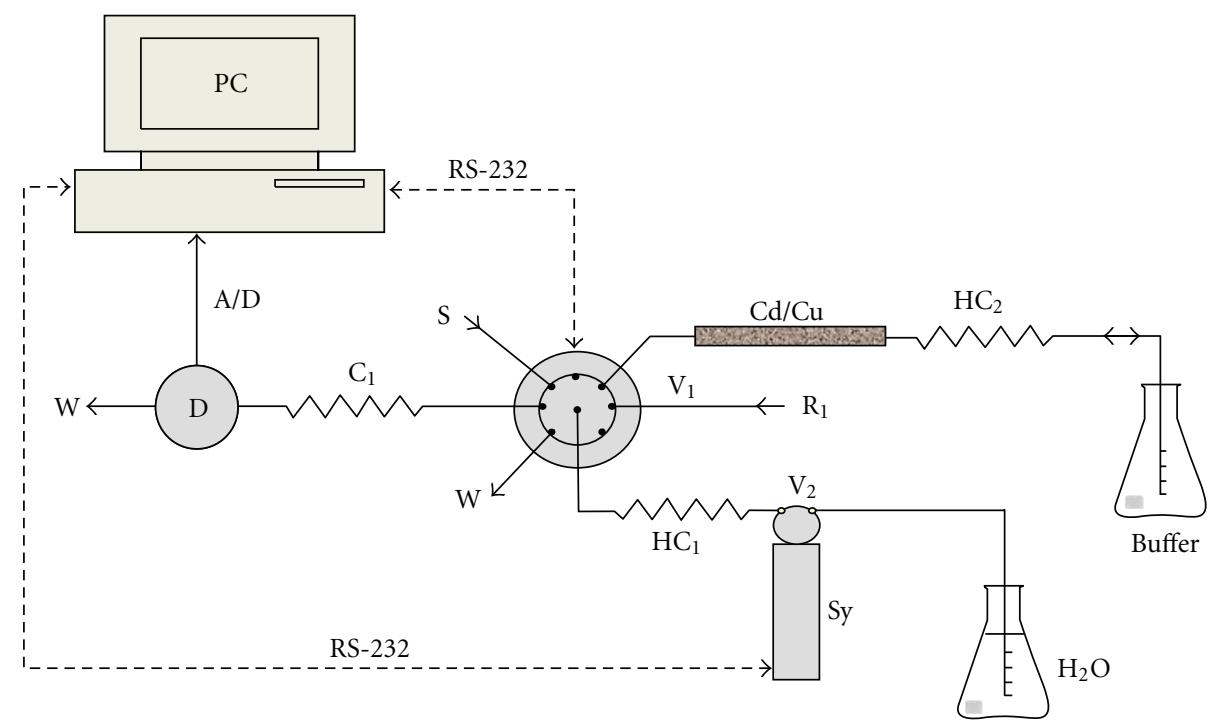

FIGURE 1: System for sequential injection analysis determinations. Sy: syringe pump, $2.5 \mathrm{~mL}$. S: sample. $\mathrm{R}_{1}$ : color reagent. $\mathrm{V}_{1}$ : selector valve with microelectric actuator. $\mathrm{V}_{2}$ : two-position valve associated with the syringe pump. $\mathrm{HC}_{1}, \mathrm{HC}_{2}$ : holding coils, $100 \mathrm{~cm} \times 0.8 \mathrm{~mm}$ ID, PFA tubing. $\mathrm{Cd} / \mathrm{Cu}$ : reducing minicolumn, $50 \mathrm{~mm} \times 2.1 \mathrm{~mm}$ ID packed with cadmium granules. $\mathrm{C}_{1}$ : mixing coil, $50 \mathrm{~cm} \times 0.8 \mathrm{~mm} \mathrm{ID}, \mathrm{PFA}$ tubing. D: detection system, spectrophotometer $(540 \mathrm{~nm})$ with $200 \mu \mathrm{L}$ inner volume flow cell. PC: personal computer with serial ports and analog to digital (A/D) interface.

TABLE 1: Routine for determination of nitrite. $V_{1}, V_{2}, R_{1}, S, C_{1}, S y$, $\mathrm{HC}_{1}$, and $\mathrm{D}$ : as indicated in Figure 1. X: not relevant. R: right. L: left. A: aspirate. P: propel. DAQ: step involving data acquisition.

\begin{tabular}{lcccccc}
\hline Step & $\mathrm{V}_{1}$ & $\mathrm{~V}_{2}$ & Operation & Destination & $\begin{array}{c}\text { Volume } \\
(\mu \mathrm{L})\end{array}$ & $\begin{array}{c}\text { Time } \\
(\mathrm{s})\end{array}$ \\
\hline 1 & $\mathrm{X}$ & $\mathrm{R}$ & $\mathrm{A}$ & $\mathrm{Sy}$ & 2083 & 10 \\
2 & $\mathrm{R}_{1}$ & $\mathrm{~L}$ & $\mathrm{~A}$ & $\mathrm{HC}_{1}$ & 167 & 1.5 \\
3 & $\mathrm{~S}$ & $\mathrm{~L}$ & $\mathrm{~A}$ & $\mathrm{HC}_{1}$ & 83 & 1.5 \\
4 & $\mathrm{R}_{1}$ & $\mathrm{~L}$ & $\mathrm{~A}$ & $\mathrm{HC}_{1}$ & 167 & 1.5 \\
5 (DAQ) & $\mathrm{C}_{1}$ & $\mathrm{~L}$ & $\mathrm{P}$ & $\mathrm{D}$ & Empty syringe & 30 \\
\hline
\end{tabular}

absorption at $540 \mathrm{~nm}$. Nitrate was reduced online to nitrite in the Cd minicolumn and the total nitrite (nitrate plus nitrite) determined colorimetrically.

The routines for the determinations are presented in Tables 1 and 2 .

The sampling frequency for this determination of nitrite was approximately 80 samples per hour.

Likewise, the program for the determination of nitrate presented steps for the reduction of nitrate present in the sample by passing it back and forth through the cadmium minicolumn, followed by color development steps as in the determination of total nitrite.

The column end is connected to a reservoir containing buffer solution via $\mathrm{HC}_{2}$, thus when the excess of water from the column is aspirated to the waste, the end portion of the column is filled with buffer solution ( $\mathrm{pH} \mathrm{8.5),} \mathrm{and} \mathrm{the}$ sample completes its forward and backward passage through the reducing agent packed in the minicolumn. The short length and the low diameter of the column avoid an excessive dilution of the sample in this reduction step.
The routine described in Table 2 corresponds to a sampling frequency of approximately 30 hour $^{-1}$ for the determination of "total nitrogen" (nitrate + nitrite).

If the program is executed for the simultaneous determination of nitrite and nitrate in one sample, the sampling frequency is approximately 20 hour $^{-1}$.

In order to preserve column lifetime, a sequence for washing the column online with buffer was programmed in the routine after each determination.

Auxiliary routines were provided in the program for the regeneration and for the copperization of the minicolumn. This was implemented by using spare ports in valve $V_{1}$ for the introduction of the appropriate reagents.

The reagents for these operations were prepared according to the ISO-IDF method [3], and the operations were carried out within the SIA system. A different routine was provided for purging the sample intake line with fresh sample and the analytical path with water. This routine was used when changing samples.

In order to check the reducing capacity of the column, a nitrite standard solution of the same concentration $\left(\mathrm{NO}_{2}-\mathrm{N}\right)$ that the most concentrated nitrate $\left(\mathrm{NO}_{3}-\mathrm{N}\right)$ standard of the calibration plot was run through the SIA system in the same conditions as samples and standards. The comparison of the signal of both solutions of identical concentration (expressed as nitrogen) allowed the verification of the reduction column efficiency. If the reduction capacity was less than $90 \%$, the column had to be regenerated.

Signals (absorbance versus time) were presented on screen and saved to file on hard disk as ASCII files (first a temporal file.txt is generated and converted to ASCII by a subroutine of the main program). The appearance of the screen is shown in Figure 2. 
TABle 2: Routine for determination of nitrate by reduction to nitrite. $\mathrm{V}_{1}, \mathrm{~V}_{2}, \mathrm{~S}, \mathrm{HC}_{1}, \mathrm{HC}_{2}, \mathrm{Cd} / \mathrm{Cu}, \mathrm{R}_{1}, \mathrm{C}_{1}, \mathrm{Sy}, \mathrm{W}$, and $\mathrm{D}$ : as indicated in Figure 1. X: not relevant. R: right. L: left. A: aspirate. P: propel. DAQ: step involving data acquisition.

\begin{tabular}{|c|c|c|c|c|c|c|}
\hline Step & $\mathrm{V}_{1}$ & $\mathrm{~V}_{2}$ & Operation & Destination & Volume $(\mu \mathrm{L})$ & Time (s) \\
\hline 1 & $\mathrm{~S}$ & $\mathrm{~L}$ & A & $\mathrm{HC}_{1}$ & 40 & 1 \\
\hline 2 & $\mathrm{Cd} / \mathrm{Cu}$ & $\mathrm{L}$ & $\mathrm{P}$ & $\mathrm{Cd} / \mathrm{Cu}$ & 40 & \multirow{4}{*}{34} \\
\hline 3 & X & $\mathrm{R}$ & A & Sy & 250 & \\
\hline 4 & $\mathrm{Cd} / \mathrm{Cu}$ & $\mathrm{L}$ & $\mathrm{P}$ & $\mathrm{Cd} / \mathrm{Cu}-\mathrm{HC}_{2}$ & 250 & \\
\hline 5 & $\mathrm{Cd} / \mathrm{Cu}$ & $\mathrm{L}$ & A & $\mathrm{HC}_{1}$ & 167 & \\
\hline 6 & W & $\mathrm{L}$ & $\mathrm{P}$ & $\mathrm{W}$ & 167 & \multirow{2}{*}{10} \\
\hline 7 & $\mathrm{X}$ & $\mathrm{R}$ & A & Sy & 1940 & \\
\hline 8 & $\mathrm{R}_{1}$ & $\mathrm{~L}$ & A & $\mathrm{HC}_{1}$ & 100 & 1.5 \\
\hline 9 & $\mathrm{Cd} / \mathrm{Cu}$ & $\mathrm{L}$ & A & $\mathrm{HC}_{1}$ & 210 & 15 \\
\hline \multirow{2}{*}{10} & $\mathrm{C}_{1}$ & $\mathrm{~L}$ & $\mathrm{P}$ & $\mathrm{C}_{1}$ & 400 & \multirow{2}{*}{14} \\
\hline & $\mathrm{C}_{1}$ & $\mathrm{~L}$ & A & $\mathrm{HC}_{1}$ & 400 & \\
\hline 11 (DAQ) & $\mathrm{C}_{1}$ & $\mathrm{~L}$ & $\mathrm{P}$ & $\mathrm{D}$ & Empty syringe & 35 \\
\hline
\end{tabular}

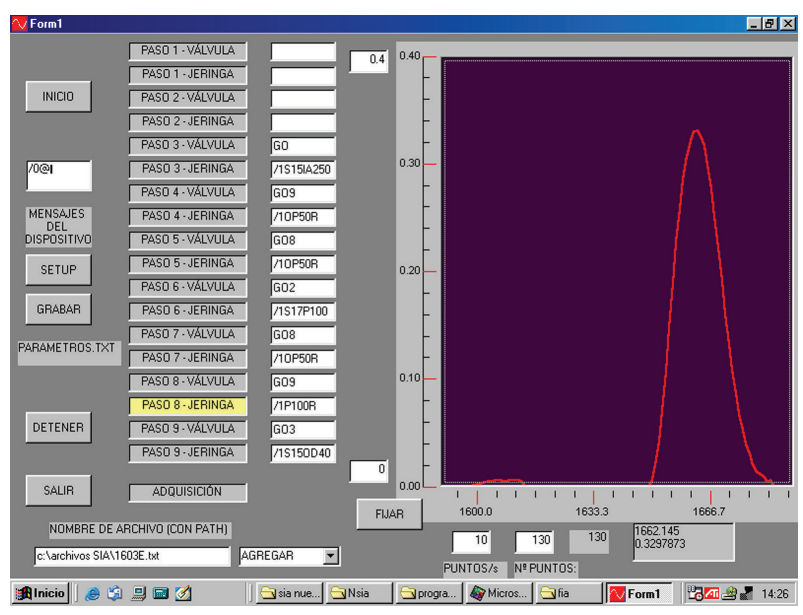

FIGURE 2: Original screen of the sequential program and peak presentation. The program was written in Spanish, the main labels, buttons, and text boxes being as follows: "INICIO": Start; "Mensajes del dispositivo": device messages; "GRABAR": Save; "DETENER": Stop; "SALIR": Exit; "Nombre del archivo (con path)": File name (with path); "FIJAR": Fix; "PUNTOS/s N ${ }^{\circ}$ PUNTOS": Points/s N ${ }^{\circ}$ of points; "PASO": Step; "VÁLVULA": Valve; "JERINGA": Syringe; "ADQUISICIÓN": Acquisition. On the right side of each step, a sentence of command is written according to the manufacturer's instructions to control the valve or the syringe via the RS-232 serial ports. The SETUP button allows entering into a service screen to run routines for regenerating or copperizing the column and rinsing the system, as well as other auxiliary routines.

Postrun processing was made with Peak Simple for Windows software (SRI Inc., Torrance, Calif, USA) which was used for establishing the baseline and measuring peak heights of the analytical signals. Finally, a printed report was obtained. The relationship between peak heights and concentrations was established by calibration curves.
TABLE 3: Figures of merit. $L D=$ detection limit, $L Q=$ quantification limit, $\mathrm{m}=$ sensitivity (slope of calibration curve). LD and LQ calculated for real samples.

\begin{tabular}{lcc}
\hline & Nitrate & Nitrite \\
\hline Parameter & Nitrate $\left(\mathrm{NO}_{3}-\mathrm{N}\right)$ & Nitrite $\left(\mathrm{NO}_{2}-\mathrm{N}\right)$ \\
\hline Limits, solution & & \\
$\mathrm{LD}\left(\mathrm{mg} \mathrm{L}^{-1}\right),(3 \sigma / \mathrm{m}, n=10)$ & 0.17 & 0.025 \\
$\mathrm{LQ}\left(\mathrm{mg} \mathrm{L}^{-1}\right),(10 \sigma / \mathrm{m}, n=10)$ & 0.55 & 0.084 \\
Limits, real samples & & \\
$\mathrm{LD}\left(\mathrm{mg} \mathrm{kg}^{-1}\right),(3 \sigma / \mathrm{m}, n=5)$ & 0.32 & 0.05 \\
LQ $\left(\mathrm{mg} \mathrm{kg}^{-1}\right),(10 \sigma / \mathrm{m}, n=5)$ & 1.08 & 0.17 \\
Precision $\left(\mathrm{s}_{r}(\%), n=5\right)$ & $1.5-3.0$ & $0.8-1.6$ \\
Linearity range $\left(\mathrm{mg} \mathrm{L}^{-1}\right)$ & $0.55-15.0$ & $0.084-1.01$ \\
Sampling rate $\left(\right.$ hour $\left.^{-1}\right)$ & $\left(r^{2}>0.999\right)$ & $\left(r^{2}>0.999\right)$ \\
\hline
\end{tabular}

\section{Results and Discussion}

3.1. Validation. The analytical methods developed were assessed for linearity, precision (repeatability), detection $(3 \sigma)$ and quantification $(10 \sigma)$ limits, and accuracy.

Linearity was studied for the two analytes by means of a 9-point calibration curve, in the range of $0.55-15.0 \mathrm{mg} \mathrm{L}^{-1}$ $\left(\mathrm{NO}_{3}-\mathrm{N}\right)$ and $0.084-1.01 \mathrm{mg} \mathrm{L}^{-1}\left(\mathrm{NO}_{2}-\mathrm{N}\right)$ which was evaluated by visual inspection of the graphical representation and by means of the regression coefficient. Linearity was found to be satisfactory for the two analytes $\left(r^{2}>0.999\right)$.

Under these conditions, the sampling frequency was 30 hour $^{-1}$ (nitrate) and 80 hour $^{-1}$ (nitrite). Results for this validation stage can be seen on Table 3 .

Six different commercial samples were used for validation, four of them representative of infant formulas found 
TABLE 4: Evaluation of accuracy.

(a) Accuracy: recovery experiments

\begin{tabular}{lcccc}
\hline \multirow{2}{*}{ Sample } & \multirow{2}{*}{ Analyte } & \multicolumn{2}{c}{ Concentration found for addition $\mathrm{C}_{2}\left(\mathrm{mg} \mathrm{L}^{-1}\right)$} & SIA recovery $(\%)$ \\
\hline Infant formula A & & Official method & SIA & 9.573 \\
& Nitrate & 5.555 & 0.208 & 105.9 \\
Infant formula B & Nitrite & 0.203 & 5.617 & 100.6 \\
& Nitrate & 5.430 & 0.209 & 103.7 \\
Infant formula for children from 0 to 6 & Nitrite & 0.202 & 5.533 & 93.8 \\
months & Nitrate & 5.520 & 0.186 & 92.0 \\
Infant formula for children from 6 to 12 & Nitrite & 0.201 & 5.380 & 96.3 \\
months & Nitrate & 5.416 & 0.210 & 104.3 \\
Nonfat milk powder & Nitrite & 0.199 & 5.800 & 100.6 \\
& Nitrate & 5.620 & 0.191 & 94.6 \\
Milk powder & Nitrite & 0.200 & 5.643 & 106.9 \\
& Nitrate & 5.632 & 0.219 & 108.5 \\
\hline
\end{tabular}

$t$-test for the recoveries

$\mathrm{H}_{0}: \mathbf{R}=100 \%$

$\mathrm{H}_{A}: \mathbf{R} \neq 100 \%$

\begin{tabular}{lcc}
\hline Parameter & Nitrate $\left(\mathrm{NO}_{3}-\mathrm{N}\right)$ & $\mathrm{Nitrite}\left(\mathrm{NO}_{2}-\mathrm{N}\right)$ \\
\hline$t$-critical $(\alpha=0.05, n=6)$ & 2.57 & 2.57 \\
$t$-experimental $(\alpha=0.05, n=6)$ & -0.19 & 0.55 \\
\hline
\end{tabular}

Recovery experiments carried out on commercial samples previously spiked with each of the analytes. $\mathrm{C}_{1}, \mathrm{C}_{2}$ : spiked concentrations. Nitrate, $\mathrm{C}_{1}=$ $3.35 \mathrm{mg} \mathrm{NO}-\mathrm{N} / \mathrm{L}, \mathrm{C}_{2}=5.58 \mathrm{mg} \mathrm{NO}-\mathrm{N} / \mathrm{L}$. Nitrite, $\mathrm{C}_{1}=0.10 \mathrm{mg} \mathrm{NO}_{2}-\mathrm{N} / \mathrm{L}, \mathrm{C}_{2}=0.20 \mathrm{mg} \mathrm{NO} 2-\mathrm{N} / \mathrm{L} . \mathrm{S}_{1}, \mathrm{~S}_{2}$ : values found for samples spiked with $\mathrm{C}_{1}$ and $C_{2}$, respectively. Recovery $(\%)$ for SIA method calculated as $\left[\left(S_{2}-S_{1}\right) /\left(C_{2}-C_{1}\right)\right] \times 100$. R: mean recovery for all samples.

(b) Accuracy: comparison with reference method, $t$-test for the differences [15]

\begin{tabular}{lcc}
\hline & $\mathrm{H}_{0}: \mathbf{d}=0$, & \\
& $\mathrm{H}_{A}: \mathbf{d} \neq 0$. & Nitrite $\left(\mathrm{NO}_{2}-\mathrm{N}\right)$ \\
\hline Parameter & Nitrate $\left(\mathrm{NO}_{3}-\mathrm{N}\right)$ & 2.57 \\
$t$-critical $(\alpha=0.05, n=6)$ & 2.57 & -0.21 \\
$t$-experimental $(\alpha=0.05, n=6)$ & -1.57 & -21 \\
\hline
\end{tabular}

Results of Student's $t$-test comparison of mean values obtained for each analyte by the proposed method and by the ISO-IDF reference method for spiking level $\mathrm{C}_{2}$. d: mean difference of the results obtained by the SIA and the reference method for all samples.

in markets in Uruguay, respectively, for infants from 0 to 6 months, 6 to 12 months and two generic infant formulas, all milk based. Nonfat milk powder and milk powder without other ingredients added were also tested.

Accuracy was evaluated by analyzing commercial samples for nitrate and nitrite by the proposed methods and by the ISO-IDF [7] method and comparing the results obtained. Since the levels obtained from the samples were below the quantification limits, it was necessary to spike the samples with the two analytes previous to the deproteinization stage. The level of this spiking is noted as $\mathrm{C}_{1}$, and the corresponding "found" value as $S_{1}$. For recovery studies, a second standard addition, noted as $\mathrm{C}_{2}$, was carried out, the corresponding "found" value being $S_{2}$. The values for the standard additions were chosen to cover the range of nitrate and nitrite content that could present a risk to the health of infants and children.

Detection $(3 \sigma)$ and quantification $(10 \sigma)$ limits calculated were expressed based on the analysis of real samples.
In the analysis of commercials samples, analytical precision $\left(s_{r}(\%), n=5\right)$ ranged from 1.5 to $3.0 \%$ for nitrate and from 0.8 to $1.6 \%$ for nitrite. The agreement between the results provided by the proposed and the reference method ranged from $0.2 \%$ to $3.4 \%$ (nitrate) and from 2.4 to $7.8 \%$ (nitrite). Submitted to Student's $t$-test [15] for the differences, the differences were found to be statistically nonsignificant, as shown on Table 4.

Accuracy was also evaluated through the standard additions method, calculating the recovery for the addition level $\mathrm{C}_{2}$. Percent recovery was calculated as $\left[\left(\mathrm{S}_{2}-\mathrm{S}_{1}\right) /\left(\mathrm{C}_{2}-\mathrm{C}_{1}\right)\right] \times$ 100 , where $S_{1}$ and $S_{2}$ are the concentrations found after spiking with concentrations $\mathrm{C}_{1}$ and $\mathrm{C}_{2}$, respectively. Results were statistically equal to $100 \%$ as shown in Table 4 .

During the development of the analytical methods, the possibility of interferences was considered. It has been reported that the determination of nitrite and nitrate by methods based on the chemistries chosen for this work can 


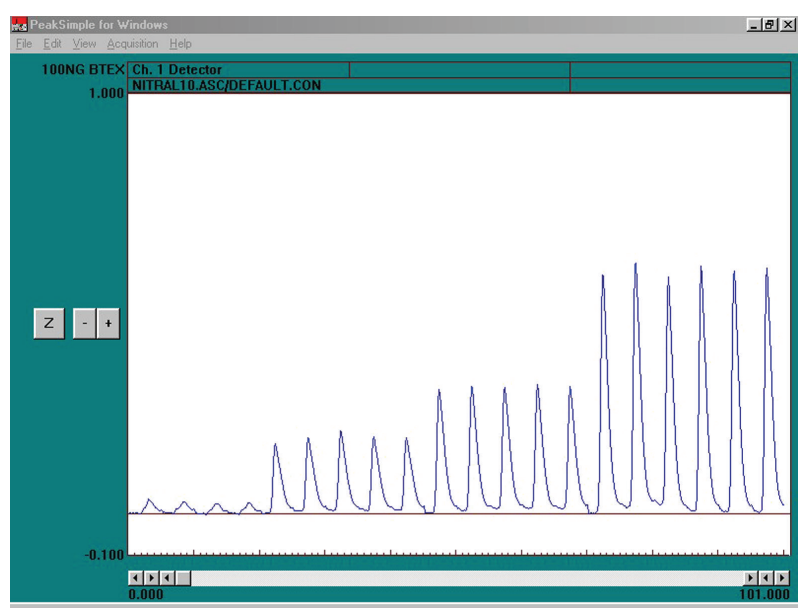

Figure 3: Peaks corresponding to the signals obtained for dissolutions of a calibration curve.

be interfered by a number of ions, especially copper [16]. However, those reports refer to more variable matrixes such as water and effluents. Milk is a matrix where most of the ions reported as potential interferants are not present at significant levels (e.g., copper $0.07 \mathrm{mg} \mathrm{L}^{-1}$ in fluid milk, or $0.9 \mathrm{mg} \mathrm{kg}^{-1}$ in milk powder), and the ISO-IDF standard methods based on the same chemistries do not foresee any of those interferences.

In the case of infant formulas, however, fortification with minerals makes necessary to consider the possibility of interference from copper, which is present in these samples at levels of 3 to $5 \mathrm{mg} \mathrm{kg}^{-1}$.

In order to evaluate this potential interference, solutions of nitrite containing 0.1 and $0.2 \mathrm{mg} \mathrm{L}^{-1}$ of $\mathrm{NO}_{2}-\mathrm{N}$ were spiked with $\mathrm{Cu}^{2+}$ at the 1 and $2 \mathrm{mg} \mathrm{L}^{-1}$ levels. The difference in absorbance between the spiked and unspiked solutions was below $2 \%$ in all cases, thus the interference of copper was considered negligible at those levels, which are much higher than those expected in fluid milk, milk powder, and infant formulas.

Figure 3 shows the screen with the peak presentation obtained for a calibration curve using the commercial program Peak Simple for Windows.

\section{General Discussion}

The SIA system performed satisfactorily in the determination of low levels of nitrate and nitrite in commercial samples. The methods developed were fast and reliable.

The specially written program consists of a pure code part and other parts associated with the objects that form the graphical interface. Only with a simple click on a button, the programmed routines were triggered, and the operator could write specific commands in text boxes. The real-time signals were drawn on the screen (Figure 2).

The routines also allowed the regeneration and copperization of the cadmium reducing minicolumn using the same system and by feeding the appropriate solutions through the minicolumn. This was achieved by means of the syri nge pump and valve, under control of specific software routines. In the official ISO-IDF method [7-9], it is necessary to regenerate the column frequently by circulating an EDTA/HCl solution. Also, after a number of samples, the copperization of the $\mathrm{Cd}$ filling is necessary. In the SIA method, the minicolumn could perform efficiently for over 50 injections, with efficiency above $90 \%$.

The sample consumption per determination was $123 \mu \mathrm{L}$, and the reagent consumption was $4.3 \mathrm{mg}$ of sulfanilamide, $0.4 \mathrm{mg}$ of NED, $63 \mathrm{mg}$ of $\mathrm{H}_{3} \mathrm{PO}_{4}, 9 \mathrm{mg}$ of $\mathrm{NH}_{4} \mathrm{Cl}$, and $1.2 \mathrm{mg}$ of EDTA. This is much lower than the consumption in the batch and FIA methods and also slightly lower than other SIA methods [14]. The carrier was purified water, while the ISO-IDF flow systems $[8,9]$ as well as other SIA proposed methods [14] use a buffer solution.

\section{Conclusions}

The proposed SIA method presents multiple benefits as opposed to the tedious traditional methods of dairy product analysis. The figures of merit obtained suggest that the method proposed could be used advantageously for the quality control of milk powder and infant formula when compared to others reported in the literature. As an additional advantage, the system is fast, efficient, and environmentally friendly for monitoring nitrate and nitrite of these samples.

\section{Acknowledgments}

The authors wish to thank CSIC (UdelaR) and PEDECIBA for financial support and Jeannette Araújo and Ramiro Pérez-Zambra for skillful laboratory work. The authors are also indebted to CONAPROLE and Gramón-Bagó for providing commercial samples of milk powder and infant formula.

\section{References}

[1] A. Tanaka, N. Nose, F. Yamada, S. Saito, and A. Watanabe, "Determination of nitrite in human, cow and market milks by gas-liquid chromatography with electron-capture detection," Journal of Chromatography, vol. 206, no. 3, pp. 531-540, 1981.

[2] V. P. Bintoro, D. Cantin-Esnault, and J. Alary, "Validation of a modified spectrophotometric method for the determination of nitrate in dry milk using 2-sec-butylphenol," The Analyst, vol. 120, no. 11, pp. 2747-2753, 1995.

[3] ISO Standard 14673:2004/IDF Standard 189:2004-Milk and milk products-Determination of nitrate and nitrite contents. International Organization for Standardization, Geneva, Switzerland, International Dairy Federation, Brussels, Belgium, 2004.

[4] P. B. Stockwell and W. T. Corns, Automatic Chemical Analysis, Taylor \& Francis, London, UK, 1996.

[5] J. Ruzicka and E. Hansen, Flow Injection Analysis, Wiley \& Sons, New York, NY, USA, 2nd edition, 1989.

[6] J. Ruzicka and G. D. Marshall, "Sequential injection: a new concept for chemical sensors, process analysis and laboratory assays," Analytica Chimica Acta, vol. 237, no. 2, pp. 329-343, 1990.

[7] ISO Standard 14673-1:2004/IDF Standard 189-1:2004- Milk and milk products-Determination of nitrate and nitrite contents. Method using cadmium reduction and spectrometry. International Organization for Standardization, Geneva, Switzerland, International Dairy Federation, Brussels, Belgium, 2004. 
[8] ISO Standard 14673-2:2004/IDF Standard 189-2:2004-Milk and milk products-Determination of nitrate and nitrite contents. Method using segmented flow analyses (Routine method). International Organization for Standardization, Geneva, Switzerland, International Dairy Federation, Brussels, Belgium, 2004.

[9] ISO Standard 14673-3:2004/IDF Standard 189-3:2004-Milk and milk products-Determination of nitrate and nitrite contents. Method using cadmium reduction and flow injection analysis with in-line dialysis (Routine method). International Organization for Standardization, Geneva, Switzerland, International Dairy Federation, Brussels, Belgium, 2004.

[10] Z. Legnerová, P. Solich, H. Sklenářová, D. Šatínský, and R. Karlíček, "Automated simultaneous monitoring of nitrate and nitrite in surface water by sequential injection analysis," Water Research, vol. 36, no. 11, pp. 2777-2783, 2002.

[11] S. Somnam, J. Jakmunee, K. Grudpan, N. Lenghor, and S. Motomizu, "Determination of nitrite and nitrate in water samples by an automated hydrodynamic sequential injection method," Analytical Sciences, vol. 24, no. 12, pp. 1599-1603, 2008.

[12] R. B. Ribeiro Mesquita, M. T. Soares Oliveira Barbosa Ferreira, R. L. Alves Segundo, C. F. Carvalho Pinheiro Teixeira, A. A. Bordalo, and A. O. Santos Silva Rangel, "Development of a sequential injection system for the determination of nitrite and nitrate in waters with different salinity: application to estuaries in NW Portugal," Analytical Methods, vol. 1, pp. 195202, 2009.

[13] R. Pérez-Olmos, J. C. Soto, N. Zárate, A. N. Araújo, J. L. F. C. Lima, and M. L. M. F. S. Saraiva, "Application of sequential injection analysis (SIA) to food analysis," Food Chemistry, vol. 90, no. 3, pp. 471-490, 2005.

[14] M. J. Reis Lima, S. M. V. Fernandes, and A. O. S. S. Rangel, "Determination of nitrate and nitrite in dairy samples by sequential injection using an in-line cadmium-reducing column," International Dairy Journal, vol. 16, no. 12, pp. 14421447, 2006.

[15] J. N. Miller and J. C. Miller, Estadística y Quimiometría en Química Analítica, Pearson Educación, Madrid, Spain, 2nd edition, 2002.

[16] L. S. Clesceri, A. E. Greenberg, and A. D. Eaton, Standard Methods for the Examination of Water and Wastewater, American Public Health Association, Washington, DC, USA, 20th edition, 1998. 


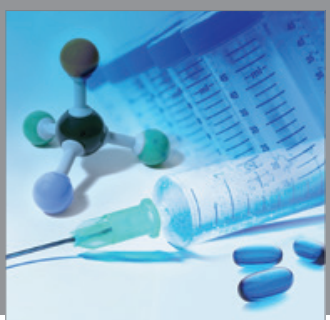

International Journal of

Medicinal Chemistry

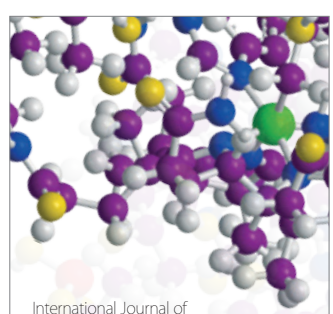

Carbohydrate Chemistry

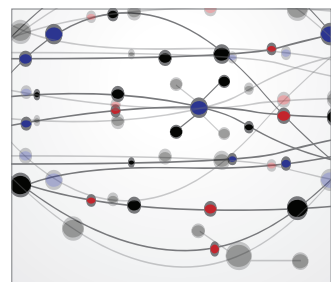

The Scientific World Journal
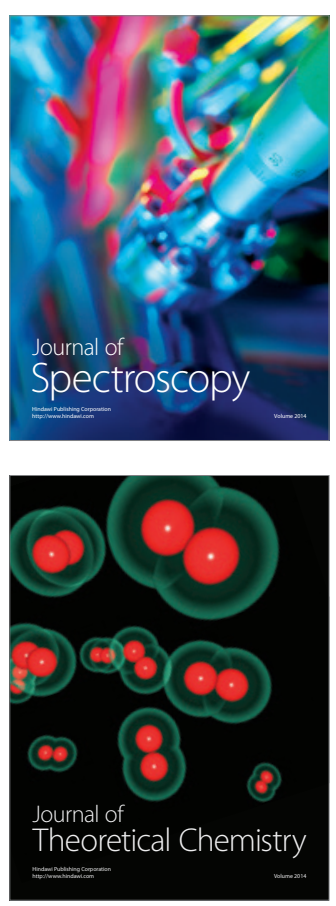
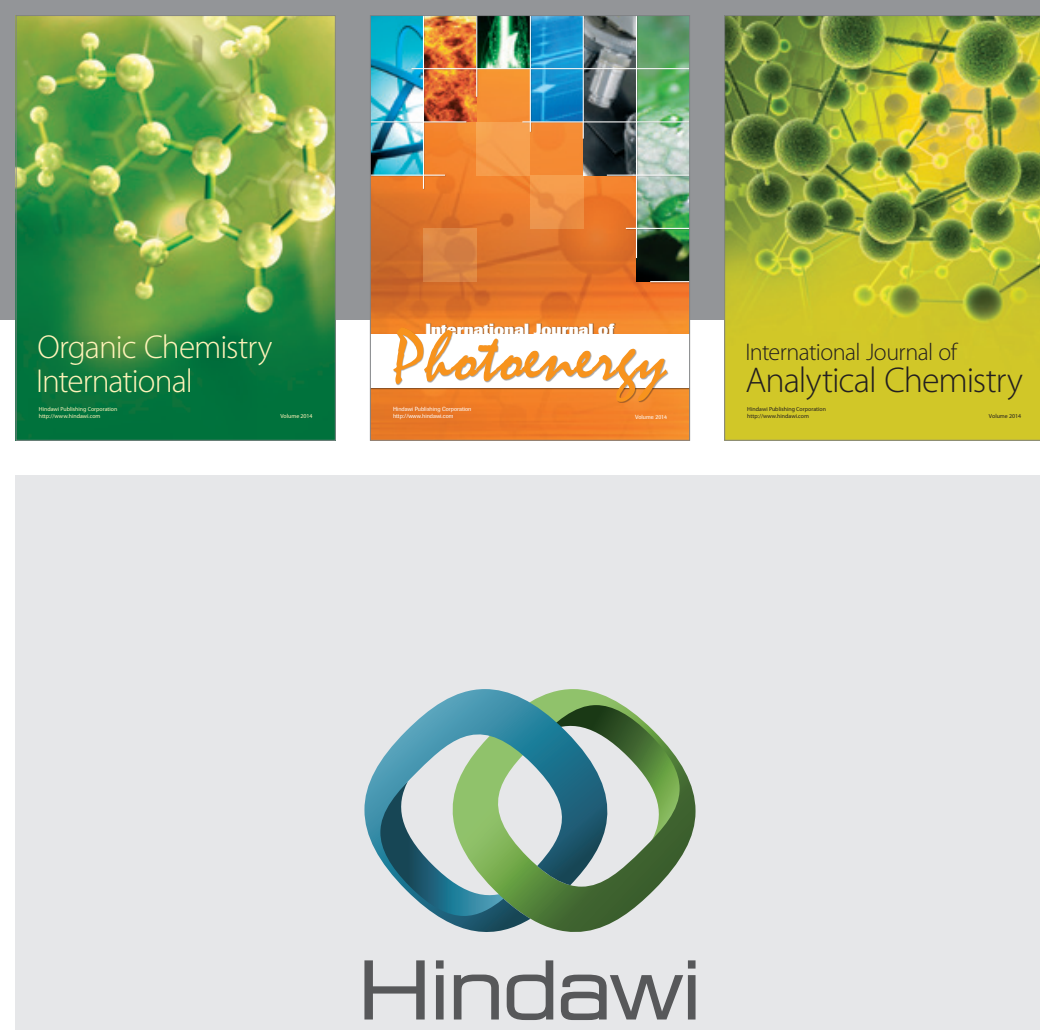

Submit your manuscripts at

http://www.hindawi.com
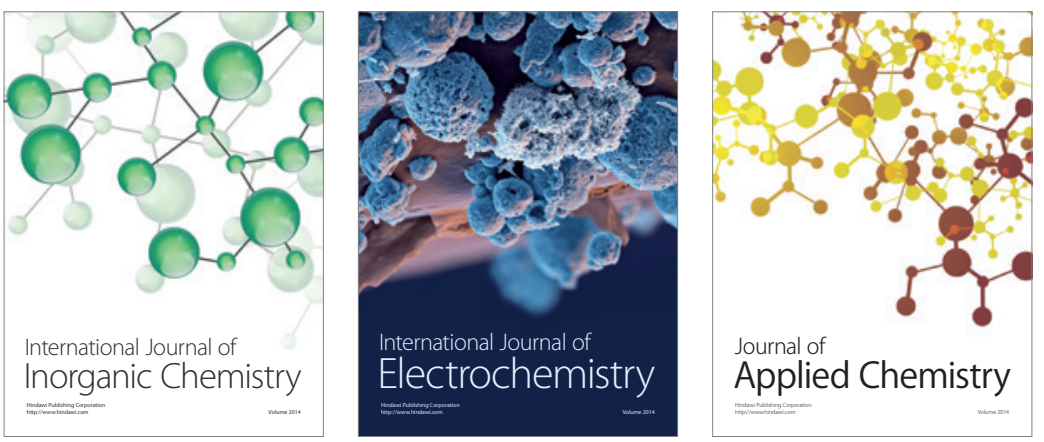

Journal of

Applied Chemistry
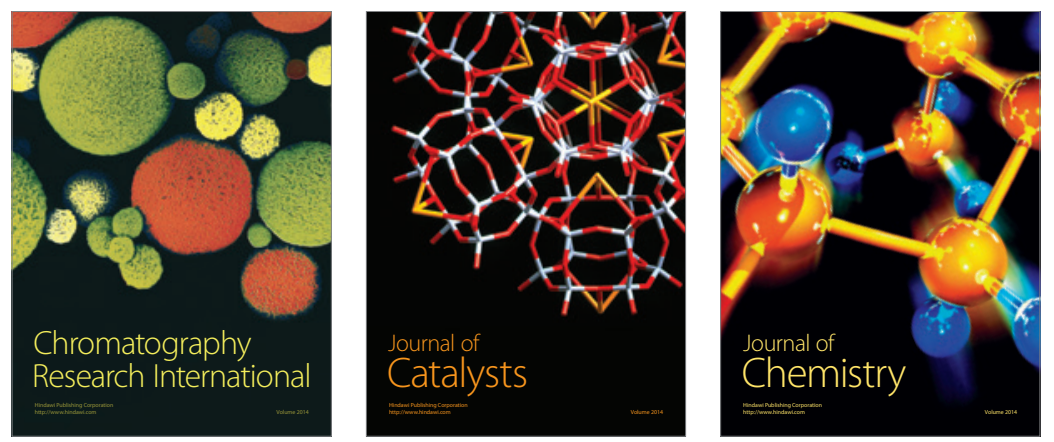
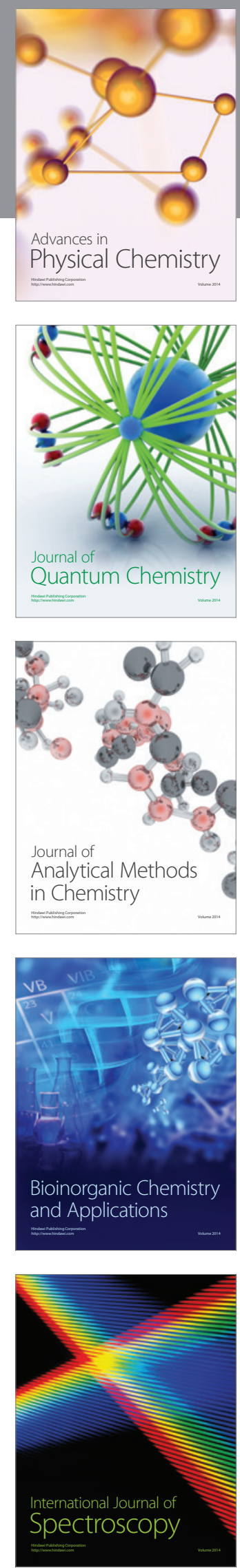